\title{
Association of AFLP and SCAR markers with common leafspot resistance in autotetraploid alfalfa (Medicago sativa)
}

\author{
Y. Wang ${ }^{1}$, B. Bi ${ }^{1}$, Q.H. Yuan', X.L. Li ${ }^{1}$ and J.M. Gao ${ }^{2}$ \\ ${ }^{1}$ Institute of Animal Science, Chinese Academy of Agricultural Sciences, \\ Beijing, China \\ ${ }^{2}$ The Key Laboratory of Crop Genetics and Breeding, \\ Department of Agronomy, Tianjin Agricultural College, Tianjin, China \\ Corresponding author: Q.H. Yuan \\ E-mail: yuanqinghua@hotmail.com
}

Genet. Mol. Res. 11 (1): 606-616 (2012)

Received August 15, 2011

Accepted January 6, 2012

Published March 14, 2012

DOI http://dx.doi.org/10.4238/2012.March.14.4

\begin{abstract}
To identify amplified fragment length polymorphism (AFLP) markers associated with resistance or susceptibility of alfalfa to common leafspot (CLS) caused by the fungus Pseudopeziza medicaginis (Dermateaceae), bulked segregant analysis was conducted based on an $\mathrm{F}_{1(\mathrm{M} \times \mathrm{M})}$ population of 93 plants and a $\mathrm{BC}_{1} \mathrm{~S}$ population of 91 plants. Three AFLP markers, ACTCAA $\mathrm{R} 206, \mathrm{TAGCAC}_{\mathrm{R} 185}$, and $\mathrm{GGACTA}_{\mathrm{S} 264}$, were found to be associated with CLS resistance or susceptibility. All three markers were found at significantly different frequencies (71.9, 80.3 and $91.8 \%$ ) compared to resistant or susceptible plants in the original population. Subsequently, these three AFLP markers were converted into three SCAR markers, ACTCAA $_{\mathrm{R} 136}, \mathrm{TAGCAC}_{\mathrm{R} 128}$ and GGACTA $_{\mathrm{S} 254}$, which are easier to employ in breeding programs. The three SCAR markers were used in a randomly selected population with $50 \%$ resistance; the probability of finding one resistant plant was increased to $67.3,66.7$ and $90.0 \%$ with markers ACTCAA $_{\mathrm{R} 136}$, TAGCAC $_{\mathrm{R} 128}$ and $\mathrm{GGACTA}_{\mathrm{S} 254}$, independently. If two of the SCAR markers were used simultaneously, the probability would be higher
\end{abstract}


than $89 \%$. The three SCAR markers identified in this study would be applicable for selection for CLS resistance in alfalfa breeding programs. Moreover, the genetic analysis indicated that CLS resistance in alfalfa is conferred by a single dominant gene.

Key words: Alfalfa; Common leafspot; Resistance; AFLP; SCAR

\section{INTRODUCTION}

Alfalfa (Medicago sativa L.) is the most widely grown forage crop worldwide, and considerable research has been performed for the genetic improvement of this crop. Cultivated alfalfa is an autotetraploid $(2 \mathrm{n}=4 \mathrm{x}=32)$ characterized by extreme heterozygosity and severe inbreeding depression (Busbice, 1968), which has been a major hindrance for the improvement of alfalfa.

Common leafspot (CLS) of alfalfa, caused by Pseudopeziza medicaginis (Lib.) Sacc, has a worldwide distribution in temperate regions wherever alfalfa is grown. Infection of alfalfa by $P$. medicaginis (Lib.) Sacc can reduce the yield and fodder quality, including palatability, digestibility, and protein content (Hanson et al., 1965; Raymond, 1969). Morgan and Parbery (1977) found that CLS could cause a decrease in the relative growth rate and leaf area ratio; reduce the rate of net assimilation in leaves and increase its rate in roots, and delay and reduce flowering, all of which resulted in the reduction of dry matter production by over $40 \%$. Morgan and Parbery (1980) also reported that when the infection of the leaf area was 15\%, the digestibility and crude protein content of infected alfalfa plants could be reduced by 14 and $16 \%$, respectively. Moreover, oestrogenic activity was stimulated in infected plants, which would have harmful effects on ovulation and pregnancy in female livestock.

Breeding of new varieties with CLS resistance is the most economical and efficient way to control diseases. The key step to achieve this is the identification and screening of disease-resistant plants. Although progress has been made in this regard, there is still a need for new techniques that can be used effectively and efficiently in large-scale screening programs. Moreover, whether such screening techniques based on inoculation can be used in this manner is unclear. The inoculation of whole plants with infested leaves in the field may enable comparisons of overall levels of host resistance in cultivars or populations. However, this method may not be suitable for identifying the most resistant individuals at low frequencies in a population, since results can vary or be inconsistent because of uniform application of inoculums and other causes. The inoculation of excised leaves or whole plants with ascospore suspensions proved to be more accurate in the selection of resistant individuals in a population (Yuan et al., 2001; Yuan and Zhang, 2003), but these two techniques are time-consuming and impractical for use in large-scale screening programs. Molecular markers that are identified to be associated with traits of interest might be valuable tools for facilitating selection. Markerassisted selection (MAS) has a great potential for increasing the efficiency of the breeding process by increasing the number of traits that can be selected in one population and by the precision with which genotypes can be selected. This method has been applied in the improvement of some crops and has been shown to be useful (Benchimol et al., 2005; Zhang et al., 2006; Barloy et al., 2007; Park et al., 2007; Nocente et al., 2007). Extensive research has been performed to identify markers associated with the desirable traits in crops. For the autotetra- 
ploid alfalfa, markers associated with disease resistance (Obert et al., 2000; Irwin et al., 2006; Mackie et al., 2007; Musial et al., 2005, 2007) and yield (Brouwer et al., 2000; Musial et al., 2006) have already been discovered.

High reproducibility, rapid generation, and high frequency of identifiable polymorphisms make the amplified fragment length polymorphism (AFLP) analysis (Vos Pieter et al., 1995) an attractive technique for indentifying polymorphic markers linked to important traits by analyzing individuals from segregating populations (Goodwin et al., 1998; Hartl et al., 1999). However, AFLP analysis is tedious and time-consuming since it involves several steps: DNA digestion, ligation, preamplification, and selective amplification. Moreover, the final polymerase chain reaction (PCR) products need to be separated by denaturing polyacrylamide gel electrophoresis, which is a complex process. Hence, AFLP markers need to be converted to easy-to-use markers such as sequence characterized amplified region (SCAR) (Paran and Michelmore, 1993) or cleaved amplified polymorphism sequences (Konieczny and Ausubel, 1993). These markers can be easily used in the MAS program.

The objective of this study was to identify AFLP markers associated with resistance or susceptibility to CLS in autotetraploid alfalfa plants by using bulked segregant analysis (Michelmore et al., 1991) and convert AFLP markers to SCAR markers. This would substantially increase the probability of enhancing trait selection in marker-assisted breeding programs.

\section{MATERIAL AND METHODS}

\section{Plant materials}

Yuan and Zhang (2000) evaluated CLS resistance in 250 alfalfa cultivars with different geographical origins; of these, 4 cultivars were selected as original materials in this study. These included Iroquois (Medicago sativa L. cv. Iroquois) from America, Saranac (Medicago sativa L. cv. Saranc) from Canada, Shahe (Medicago sativa L. cv. Shahe) from Hebei of China, and Jingyang (Medicago sativa L. cv. Jingyang) from Shanxi of China. Iroquois had high CLS resistance and the remaining 3 had moderate CLS resistance. For each cultivar, 200 plants were planted and evaluated for CLS resistance. Six plants with high resistance were selected from Iroquois, Shahe, and Saranc and were designated as I601R, I602R, SH601R, SH602R, SR601R, and SR602R. Six plants with high susceptibility were selected from Shahe and Jingyang and were designated as SH601S, SH602S, SH603S, J601S, J602S, and J603S. Four plants with moderate resistance were selected from Iroquois and Shahe and were designated as I601M, I602M, SH601M, and SH602M. One $\mathrm{F}_{1(\mathrm{M} \times \mathrm{M})}$ population $(\mathrm{I} 602 \mathrm{M} \times \mathrm{SH} 602 \mathrm{M})$ and one $\mathrm{BC}_{1} \mathrm{~S}$ population $[(\mathrm{SR} 602 \mathrm{R} \times \mathrm{SH} 603 \mathrm{~S}) \times \mathrm{SH} 603 \mathrm{~S}]$ were constructed as segregating populations in our study. One $\mathrm{BC}_{1} \mathrm{~S}$ population $[(\mathrm{SR} 602 \mathrm{R} \times \mathrm{SH} 603 \mathrm{~S}) \times \mathrm{SR} 602 \mathrm{R}]$ and one $\mathrm{F}_{1(\mathrm{R} \times \mathrm{S})}$ population (SR602R $\left.\times \mathrm{SH} 603 \mathrm{~S}\right)$ were constructed for studying inheritance of CLS resistance. Two resistant $\times$ resistant crosses $($ I602R $\times$ SR602R and SH602R $\times$ SR601R) and two susceptible $\times$ susceptible crosses $($ SH603S $\times$ J603S and J601S $\times$ SH601S) were made for the validation of AFLP markers found in the $\mathrm{F}_{1}$ and $\mathrm{BC}_{1}$ population. Moreover, a randomly selected population comprised 4 alfalfa cultivars, Sardi, Xinjiangdaye, Longmu 801, and Zhongmu No. 1, which were planted for the validation of SCAR markers. 


\section{Disease evaluation}

The isolate of $P$. medicaginis (Lib.) Sacc was obtained from infected plots of Baoding alfalfa in the nursery of the Institute of Animal Science, Chinese Academy of Agricultural Sciences, Beijing, and maintained on infected Baoding plants in the glasshouse.

Two hundred plants from the $\mathrm{BC}_{1}$ population and 200 plants from the $\mathrm{F}_{1}$ population were screened for reaction to $P$. medicaginis (Lib.) Sacc by using the disease evaluation test described by Fang et al. (2008).

On the 20 th day after inoculation, disease severity for each leaflet was visually evaluated and recorded on a scale of 0-5 $(0=$ no leaf spot, $1=1-3$ leaf spots, $2=4-6$ leaf spots, $3=$ 7-10 leaf spots, $4=11-15$ leaf spots, and $5=$ more than 15 leaf spots). Next, the disease severity for one whole plant was calculated using the disease index (DI) equation:

$$
\mathrm{DI}=\left[\sum\left(\mathrm{i} \times \mathrm{N}_{\mathrm{i}}\right) /(5 \times \mathrm{N})\right] \times 100 \%
$$

where $i$ refers to the score of disease severity for leaflets, $N_{i}$ indicates the number of leaflets with the score of $i$, and $N$ indicates the total number of leaflets for one plant. According to the value of DI, individual plants were classified as immune $(\mathrm{DI}=0)$, highly resistant $(\mathrm{HR}, 0<$ $\mathrm{DI} \leq 10.0 \%$ ), moderately resistant (MR, $10.0 \%<\mathrm{DI} \leq 20.0 \%)$, moderately susceptible (MS, $20.0 \%<\mathrm{DI} \leq 30.0 \%$ ), and highly susceptible (HS, DI $>30.0 \%$ ).

For the 2 segregating populations, 10 resistant and 10 susceptible plants were selected to construct bulked DNA pools. For the 2 resistant $\times$ resistant crosses, 200 plants were planted, and 32 resistant plants were selected by CLS disease evaluation. For the 2 susceptible $\times$ susceptible crosses, 200 plants were planted, and 32 susceptible plants were selected by CLS disease evaluation. For the randomly selected population, 10 resistant and 10 susceptible plants were selected from each cultivar via disease evaluation to form a new population containing 40 resistant plants and 40 susceptible plants.

\section{DNA isolation and AFLP assay}

DNA was extracted from each plant according to the protocol of Doyle and Doyle (1990), with slight modification. Samples were quantified using 1\% agarose gel electrophoresis with $\lambda$-DNA as contrast standards and diluted to a concentration of $10 \mathrm{ng} / \mu \mathrm{L}$.

Bulked DNA samples, consisting of equal amounts of DNA from either 10 resistant or 10 susceptible plants, were developed. AFLP analysis with 64 primer combinations was performed to identify molecular markers associated with CLS disease resistance or susceptibility.

The enzyme combination Pst $\mathrm{I} / \mathrm{MseI}$ was used to generate templates for AFLP reactions. Genomic DNA $(0.15 \mu \mathrm{g})$ was incubated at $37^{\circ} \mathrm{C}$ for $6 \mathrm{~h}$ with $1.5 \mathrm{U}$ Pst $\mathrm{I}$ and $1.5 \mathrm{U}$ MseI in $20 \mu \mathrm{L} 10 \mathrm{mM}$ Tris-HAc, pH 7.5, $10 \mathrm{mM} \mathrm{MgAc}, 50 \mathrm{mM} \mathrm{KAc}$, and $50 \mathrm{ng} / \mu \mathrm{L}$ bovine serum albumin (BSA). Next, $5 \mu \mathrm{L}$ of a solution containing 3 pmol Pst I-adapter, 30 pmol MseIadapter, $1 \mathrm{U}$ T4 DNA-ligase, $0.2 \mathrm{mM}$ ATP in $10 \mathrm{mM}$ Tris-HAc, pH 7.5, $10 \mathrm{mM} \mathrm{MgAc}, 50 \mathrm{mM}$ $\mathrm{KAc}$, and $50 \mathrm{ng} / \mu \mathrm{L}$ BSA was added, and the mixture was incubated at $20^{\circ} \mathrm{C}$ overnight. Preamplification was performed in volumes of $25 \mu \mathrm{L}$ containing $2 \mu \mathrm{L}$ reaction mixture produced by ligation, $0.75 \mu \mathrm{M}$ PstI-primer, $0.75 \mu \mathrm{M}$ MseI-primer, $0.2 \mathrm{mM}$ dNTPs, $0.6 \mathrm{U}$ Taq DNA polymerase, $10 \mathrm{mM}$ Tris- $\mathrm{HCl}, \mathrm{pH} 8.3,50 \mathrm{mM} \mathrm{KCl}$, and $1.5 \mathrm{mM} \mathrm{MgCl}_{2}$. After preamplifica- 
tion, the reaction mixture was diluted 10 -fold with $\mathrm{ddH}_{2} \mathrm{O}$ and used as template for selective amplification. The selective amplification was performed in volumes of $20 \mu \mathrm{L}$ containing $5 \mu \mathrm{L}$ templates, $0.15 \mu \mathrm{M}$ PstI-primer, $0.15 \mu \mathrm{M}$ MseI-primer, $0.5 \mathrm{U}$ Taq DNA polymerase, and the same concentration of other ingredients used for the preamplification step. All amplification reactions were performed using a PTC-100 96-well thermal controller (MJ Research, Waterton, MA, USA) following the protocol of Vos Pieter et al. (1995).

After amplification, the PCR product was diluted 1:1 with loading buffer $(98 \%$ formamide, $10 \mathrm{mM}$ ethylenediaminetetraacetic acid (EDTA), 0.1\% bromophenol blue, $0.1 \% \mathrm{xy}$ lene cyanol), and $3 \mu \mathrm{L}$ was loaded on a $6 \%$ denaturing polyacrylamide gel. Samples were run at 110 watts constant power for $30 \mathrm{~min}$ and 90 watts constant power for $120 \mathrm{~min}$. The gel was then silver stained according to the procedure of Bassam et al. (1991) and manually scored for the presence or absence of specific bands.

\section{Identification of AFLP markers}

Specific AFLP fragments were tested for significant association with disease reaction in the segregating population, and various hybridization populations were produced by crossing of resistant $\times$ resistant and susceptible $\times$ susceptible based on a contingency $\chi^{2}$ analysis with a significance level of 0.01 .

\section{Sequencing and SCAR development}

Fragments with strong intensity that were significantly associated with either resistance or susceptibility were extracted from the gel and cloned. The piece of gel containing the fragment was placed in a $0.2-\mathrm{mL}$ tube containing $20 \mu \mathrm{L} 10 \mathrm{X} \mathrm{TE}$, heated at $95^{\circ} \mathrm{C}$ for $10 \mathrm{~min}$, ground with a pipette tip, heated at $95^{\circ} \mathrm{C}$ for $10 \mathrm{~min}$, centrifuged for $10 \mathrm{~s}$, and the supernatant was recovered. Next, $1 \mu \mathrm{L}$ of the supernatant was used as template for reamplification. The PCR product was extracted from the agarose gel, purified using TaKaRa Agarose Gel DNA Purification Kit Ver. 2.0 (TaKaRa, Japan) according to the manufacturer recommendation, and cloned using the TA cloning kit (TaKaRa). The sequencing program was performed by Shanghai Sangon Co. Ltd., and sequence homology was analyzed at http://www.ncbi.nlm.nih. gov of National Center for Bioinformatics (NCBI) by using the BLASTN program. Specific PCR primers were designed using the Primer the Premier 5.0 software. These primers were then tested on the randomly selected population that contained 40 resistant and 40 susceptible plants to analyze the marker of interest for co-segregation with the desired trait.

\section{RESULTS}

\section{Genetic analysis for CLS resistance}

SR602R was classified as a resistant parent, while SH603S was classified as a susceptible parent. In all, $87.3 \%$ of the $\mathrm{F}_{1(\mathrm{R} \times \mathrm{S})}$ plants generated by the hybridization of SR602R $\times$ SH603S and $86.8 \%$ of the $\mathrm{BC}_{1} \mathrm{R}$ plants generated by the hybridization of (SR602R $\times$ SH603S) $\times$ SR602R were rated as resistant. This indicated that resistance to the pathogen strain employed here was dominance to susceptibility. Of the $199 \mathrm{BC}_{1} \mathrm{~S}$ plants, the segregations fit a 5:1 
ratio $\left(\chi^{2}=1.600, P=0.206\right)$, with 160 plants classified as resistant and 39 as susceptible. Of the $177 \mathrm{~F}_{1(\mathrm{M} \times \mathrm{M})}$ plants, the segregations fit a $3: 1$ ratio $\left(\chi^{2}=1.373, \mathrm{P}=0.241\right)$, with 126 plants classified as resistant and 51 as susceptible (Table 1). The DI distribution of $\mathrm{BC}_{1} \mathrm{~S}$ and $\mathrm{F}_{1(\mathrm{M} \times \mathrm{M})}$ populations (Figure 1 and Figure 2), which exhibited 2 peaks, showed CLS resistance to the strain and was conferred by a single dominant gene.

\begin{tabular}{|c|c|c|c|c|c|c|c|c|c|c|}
\hline \multirow[t]{2}{*}{ Population } & \multirow[t]{2}{*}{ Total plants } & \multicolumn{3}{|c|}{ Resistant plants } & \multicolumn{2}{|c|}{$\underline{\text { Susceptible plants }}$} & \multirow[t]{2}{*}{ Observed ratio of R:S } & \multirow[t]{2}{*}{ Expected ratio of R:S } & \multirow[t]{2}{*}{$\chi^{2}$} & \multirow[t]{2}{*}{$\mathrm{P}$} \\
\hline & & I & HR & MR & MS & $\mathrm{HS}$ & & & & \\
\hline & 126 & 0 & 46 & 64 & 15 & 1 & $110: 16$ & - & - & - \\
\hline $\mathrm{BC}_{1} \mathrm{R}$ & 152 & 2 & 52 & 78 & 17 & 3 & $132: 20$ & - & - & - \\
\hline $\mathrm{BC}_{1} \mathrm{~S}$ & 199 & 2 & 93 & 65 & 32 & 7 & $160: 39$ & $5: 1$ & 1.600 & 0.206 \\
\hline $\mathrm{F}_{1(\mathrm{M} \times \mathrm{M})}$ & 177 & 2 & 73 & 51 & 44 & 7 & $126: 51$ & $3: 1 / 11: 1 / 35: 1$ & $\chi_{(3: 1)}^{2}=1.373$ & 0.241 \\
\hline
\end{tabular}

${ }^{\mathrm{a}} \mathrm{F}_{1(\mathrm{R} \times \mathrm{S})}=$ population conducted by the hybridization of resistant parent and susceptible parent, $\mathrm{SR} 602 \mathrm{R} \times \mathrm{SH} 603 \mathrm{~S}$; $\mathrm{BC}_{1} \mathrm{R}=$ population of $\mathrm{BC}_{1}$ backcrossed with resistant parent; $\mathrm{BC}_{1} \mathrm{~S}=$ population of $\mathrm{BC}_{1}$ backcrossed with susceptible parent; $\mathrm{F}_{1 \mathrm{M} \times \mathrm{M})}=$ population conducted by the hybridization of moderate-resistant parent and moderatesusceptible parent, I602M $\times$ SH602M. HR and MR = highly and moderately resistance; MS and HS = moderately and highly susceptible.

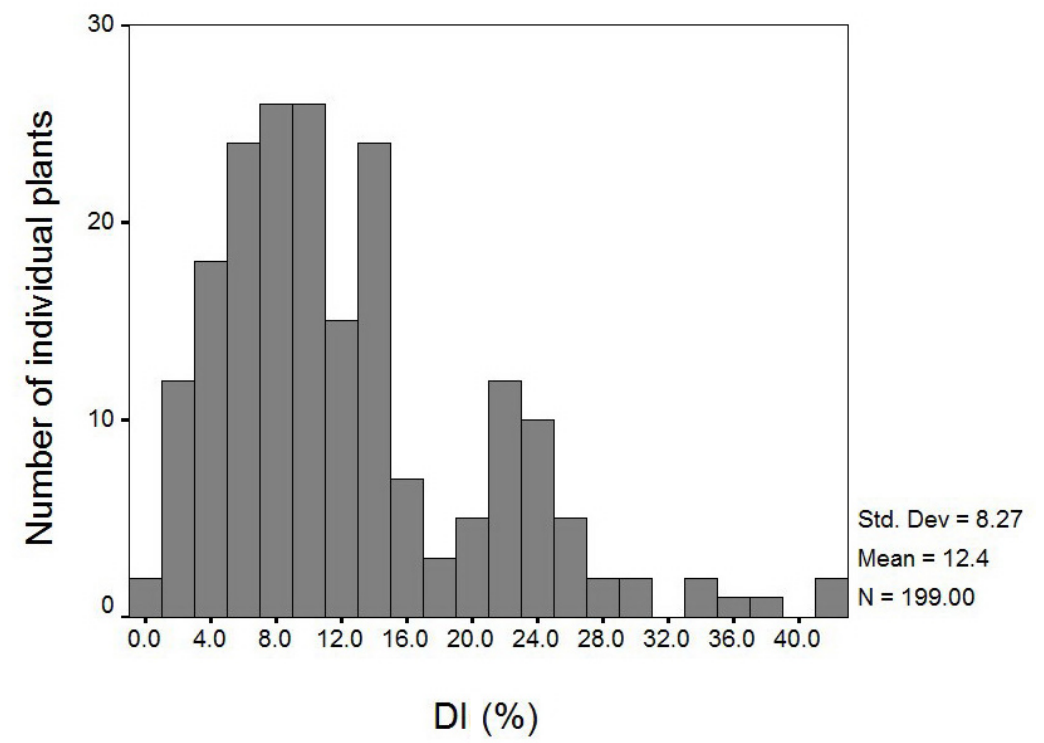

Figure 1. Distribution of the disease index (DI) in the $\mathrm{BC}_{1} \mathrm{~S}$ population.

\section{AFLP markers associated with CLS resistance or susceptibility}

For the bulked DNA samples of the $\mathrm{BC}_{1} \mathrm{~S}$ and $\mathrm{F}_{1(\mathrm{M} \times \mathrm{M})}$ population, $10 \mathrm{AFLP}$ primer combinations yielded about 233 amplified bands per plant in the $\mathrm{BC}_{1} \mathrm{~S}$ population and 205 bands in the $\mathrm{F}_{1(\mathrm{M} \times \mathrm{M})}$ population. Nineteen of the AFLP fragments were found to be associated with CLS in the bulked DNA samples. Of these fragments, 16 were found to be associated with either re- 


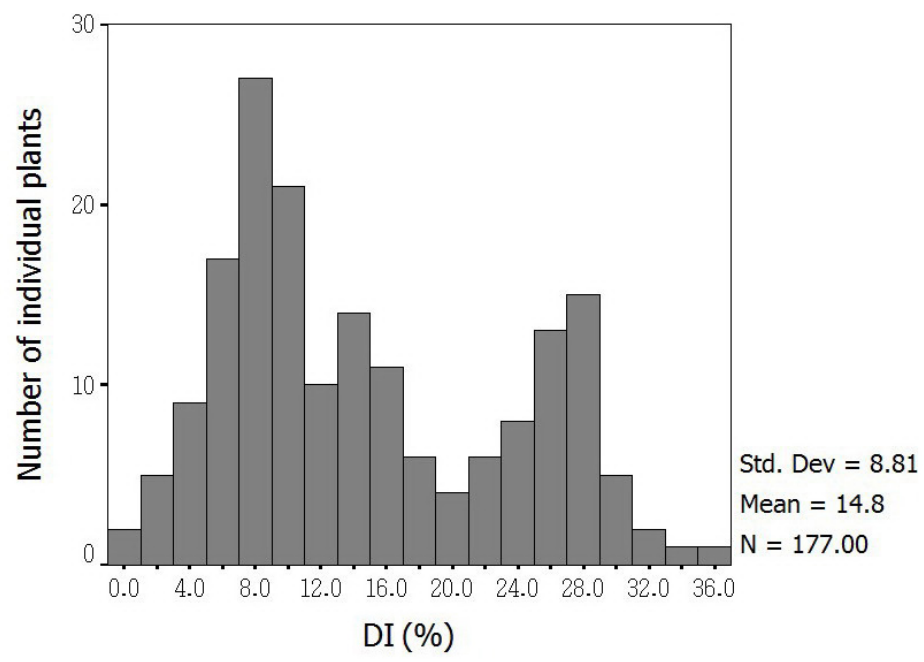

Figure 2. Distribution of the disease index (DI) in the $\mathrm{F}_{1(\mathrm{M} \times \mathrm{M})}$ population.

sistance or susceptibility, but there was a very small difference between the resistant and susceptible plants in the base population where they originated from (data not shown). These fragments were not analyzed further. The remaining 3 fragments were likely to be useful in marker-assisted identification of resistant or susceptible plants. The fragments were cloned and sequenced and were found to be 206, 185, and $264 \mathrm{bp}$ in length. They were then designated (based on the 3 selective nucleotides for each primer) as $\mathrm{ACTCAA}_{\mathrm{R} 206}, \mathrm{TAGCAC}_{\mathrm{R} 185}$, and $\mathrm{GGACTA}_{\mathrm{S} 264}$ (Figure 3).

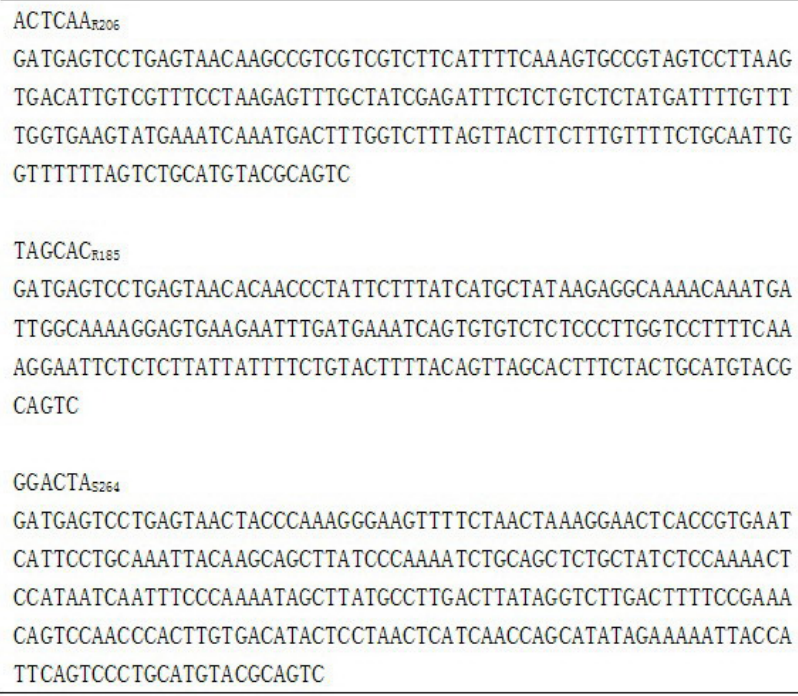

Figure 3. DNA sequences of AFLP associated with resistance or susceptibility of common leafspot. The name of the fragments indicate the 3 selective nucleotides from the PstI site and the MseI site; the subscripted letters "S" or " $R$ " indicate whether the fragment was associated with susceptibility or resistance; the numeric subscript indicates the length of the fragment. 
Marker ACTCAA $_{\text {R206 }}$ occurred in a significantly higher proportion in resistant plants $(95.7 \%)$ than in susceptible plants $(23.8 \%)$ in the $\mathrm{BC}_{1} \mathrm{~S}$ population. $\mathrm{TAGCAC}_{\mathrm{R} 185}$ occurred in a significantly higher proportion in resistant plants $(82.7 \%)$ than in susceptible plants $(2.4 \%)$ in

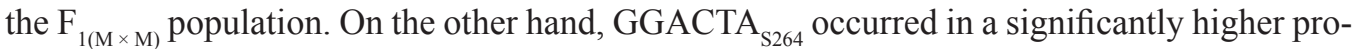
portion in susceptible plants $(97.6 \%)$ than in resistant plants $(5.8 \%)$ in the $\mathrm{F}_{1(\mathrm{M} \times \mathrm{M})}$ population (Table 2). ACTCAA $\mathrm{R} 206, \mathrm{TAGCAC}_{\mathrm{R} 185}$, and GGACTA $\mathrm{S} 264$ showed significant association with the resistant or susceptible genotypes with $\chi^{2}$ of $50.6,59.2$, and 77.7 , respectively. The difference in the frequencies of occurrence of the markers between the resistant and susceptible plants of the original, hybridization, and random populations were $65.7,62.3$, and $73.5 \%$, respectively (Table 2). This suggests that the markers would be valuable in MAS programs. The BLASTN analysis revealed that the 3 AFLP markers had a high identity with the corresponding sequences of Medicago truncatula (CT962504.10, AC135605.25, and CU468825.14), which indicated that they all originated from the alfalfa genome.

\begin{tabular}{|c|c|c|c|c|c|c|c|c|}
\hline \multirow[t]{2}{*}{ Type of population } & \multirow[t]{2}{*}{ Total plants } & \multirow{2}{*}{$\begin{array}{l}\text { Resistant: } \\
\text { Susceptible }\end{array}$} & \multicolumn{2}{|c|}{ ACTCAA $_{\mathrm{R} 206}(\%)$} & \multicolumn{2}{|c|}{ TAGCAC $_{\mathrm{R} 185}(\%)$} & \multicolumn{2}{|c|}{ GGACTA $_{\mathrm{S} 264}(\%)$} \\
\hline & & & Resistant & Susceptible & Resistant & Susceptible & Resistant & Susceptible \\
\hline $\mathrm{BC}_{1} \mathrm{~S}$ & 91 & $70: 21$ & 95.7 & 23.8 & - & - & - & - \\
\hline $\mathrm{F}_{1(\mathrm{M} \times \mathrm{M})}$ & 93 & $52: 41$ & - & - & 82.7 & 2.4 & 5.8 & 97.6 \\
\hline $\mathrm{R} \times \mathrm{R}$ and $\mathrm{S} \times \mathrm{S}$ & 64 & $32: 32$ & 87.5 & 15.6 & 78.1 & 18.7 & 9.4 & 81.3 \\
\hline Random & 80 & $40: 40$ & 87.5 & 35.0 & 100.0 & 52.5 & 40.0 & 92.5 \\
\hline Total & 328 & 194:134 & 91.5 & 25.8 & 87.1 & 24.8 & 17.7 & 91.2 \\
\hline
\end{tabular}

\section{Development of SCAR markers}

Three primers specific for the 3 AFLP markers, ACTCAA ${ }_{\mathrm{R} 206}, \mathrm{TAGCAC}_{\mathrm{R} 185}$, and GGACTA $_{\mathrm{S} 264}$, resulted in the amplification of 3 fragments of lengths 136,128 , and $254 \mathrm{bp}$, respectively. The markers were then designated as $\mathrm{ACTCAA}_{\mathrm{R} 136}, \mathrm{TAGCAC}_{\mathrm{R} 128}$, and $\mathrm{GGACTA}_{\mathrm{S} 254}$. The 3 SCAR markers were validated in the randomly selected population with $50 \%$ resistance. The results showed that all the markers were significantly associated with the resistance or susceptible phenotypes. $\mathrm{ACTCAA}_{\mathrm{R} 136}$ and $\mathrm{TAGCAC}_{\mathrm{R} 128}$ occurred in a higher proportion in resistant plants ( 82.5 and $95.0 \%$ ) than in susceptible plants (40.0 and $47.5 \%$ ), while GGACTA S254 $_{2}$ occurred in a higher proportion in susceptible plants $(92.5 \%)$ than in resistant plants $(32.5 \%)$ (Table 3, Figure 4). The 3 SCAR markers would be helpful in selection programs.

Table 3. Presence of sequence characterized amplified region (SCAR) markers in the randomly selected population.

\begin{tabular}{|c|c|c|c|c|}
\hline \multirow[t]{2}{*}{ SCAR markers $^{\mathrm{a}}$} & \multirow[t]{2}{*}{ Primer sequences $\left(5^{\prime}-3^{\prime}\right)$} & \multicolumn{2}{|c|}{ Marker existed (\%) } & \multirow[t]{2}{*}{ Conditional probability } \\
\hline & & 40 resistant plants & 40 susceptible plants & \\
\hline ACTCAA $_{\mathrm{R} 136}$ & $\begin{array}{l}\text { F: TGTCGTTTCCTAAGAGTTTG } \\
\text { R: GCGTACATGCAGACTAAAAAACC }\end{array}$ & 82.5 & 40.0 & $67.3 \%$ \\
\hline TAGCAC $_{\mathrm{R} 128}$ & $\begin{array}{l}\text { F: CAAATGATTGGCAAAAGGAGT } \\
\text { R: GCGTACATGCAGTAGAAAGTGC }\end{array}$ & 95.0 & 47.5 & $66.7 \%$ \\
\hline GGACTA $_{\mathrm{S} 254}$ & $\begin{array}{l}\text { F: AGTCCTGAGTAACTACCCAAAGG } \\
\text { R: GTACATGCAGGGACTGAATGGTA }\end{array}$ & 32.5 & 92.5 & $90.0 \%$ \\
\hline
\end{tabular}

aThe names of the SCAR markers indicate the 3 selective nucleotides from the PstI site and the MseI site; the subscripted letters "S" or "R" indicate whether the fragment was associated with susceptibility or resistance; the numeric subscript indicates the length of the SCAR marker. 

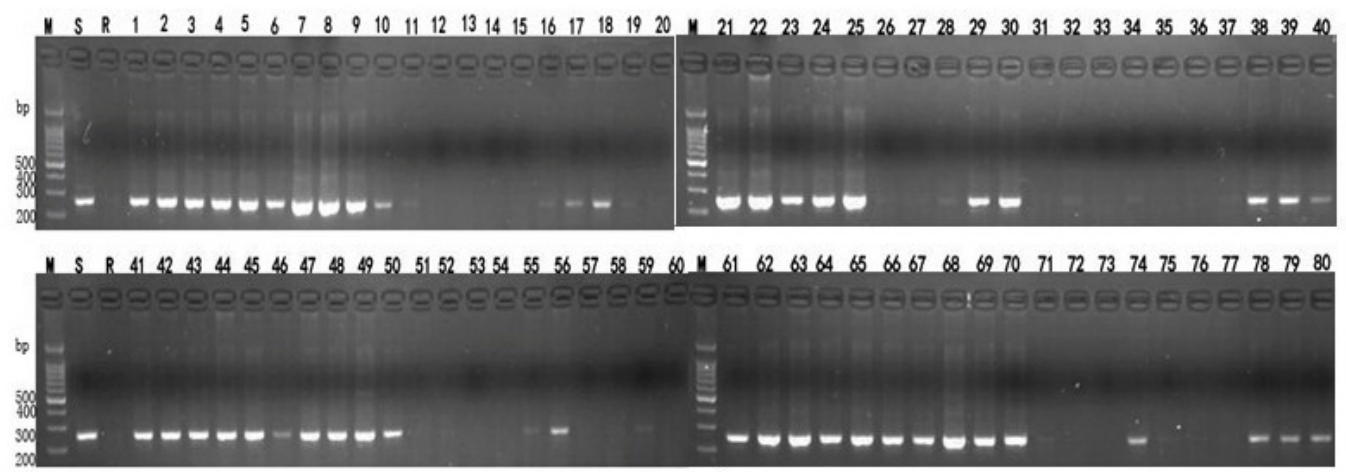

Figure 4. Validation of the SCAR marker GGACTA ${ }_{\mathrm{S} 254}$ in the randomly selected population. Lane $M=100$-bp DNA ladder; lane $S=$ the susceptible bulked DNA sample of the $\mathrm{F}_{1}$ population; lane $R=$ the resistant bulked DNA sample of the $\mathrm{F}_{1}$ population; lanes 1-10 = susceptible plants from Xinjiangdaye; lanes 11-20= resistant plants from Xinjiangdaye; lanes 21-30= susceptible plants from Sardi; lanes 31-40= resistant plants from Sardi; lanes 41-50 $=$ susceptible plants from Longmu 801; lanes 51-60= resistant plants from Longmu 801; lanes 61-70= susceptible plants from Zhongmu No. 1; lanes 71-80= resistant plants from Zhongmu No. 1.

\section{DISCUSSION}

The ideal method for the identification of molecular markers associated with the desirable traits would involve the development of near-isogenic lines differing only in the traits of interest. The commonly used procedure for achieving this is the production of a segregating population of $\mathrm{F}_{2}$ or later individuals or production of recombinant inbred lines. However, alfalfa is naturally outcrossing plant; hence, the development of segregating populations of alfalfa is difficult or impossible due to the severe inbreeding depression. The $\mathrm{F}_{1}$ and $\mathrm{BC}_{1}$ populations could be successful used in the identification of molecular markers associated with traits of interest in the autotetraploid alfalfa (Brouwer, 2000; Mackie et al., 2007; Musial, 2005 , 2007). Therefore, we used both $\mathrm{F}_{1}$ and $\mathrm{BC}_{1}$ populations as segregating population in our study to enhance the probability of discovering desirable molecular markers. Three AFLP markers, ACTCAA $_{\mathrm{R} 206}, \mathrm{TAGCAC}_{\mathrm{R} 185}$, and $\mathrm{GGACTA}_{\mathrm{S} 264}$, were found to be associated with CLS resistance or susceptibility, and they occurred in a significantly higher proportion either in the resistant and susceptible plants, irrespective of whether in the base population or in the verification population (Table 2).

The 3 SCAR markers specific for the 3 AFLP markers showed a significant difference of occurrence between the resistant and susceptible plants in the randomly selected population (occurrence rate, 42.5, 47.5, and 60\%). According to the method of Skinner et al. (2000), the conditional probability of the $3 \mathrm{SCAR}$ markers was calculated. For markers ACTCAA $\mathrm{R}_{\mathrm{R} 136}$ and $\mathrm{TAGCAC}_{\mathrm{R} 128}$, which occurred in significantly higher proportion in the resistant population than in the susceptible population, the probability of finding a resistant plant with the markers would be increased to 67.3 and $66.7 \%$, respectively. For marker GGACTA ${ }_{\mathrm{s} 254}$, which occurred in significantly higher proportion in the susceptible population than in the resistant population, the lack of the marker would be considered as desirable. When it was used in a population with $50 \%$ resistance, the probability of finding a resistant plant with the desirable marker would be increased to $90.0 \%$. Hence, marker GGACTA $_{\mathrm{S} 254}$ has a higher probability in 
selecting resistant plants than the other 2 markers and would be more valuable in breeding programs. If the 3 markers were independent and either of both the markers were used simultaneously, the probability of missing a resistant plant was $(1-0.673)(1-0.667)=0.1089 \approx$ 0.109 for markers ACTCAA ${ }_{\mathrm{R} 136}$ and $\mathrm{TAGCAC}_{\mathrm{R} 128},(1-0.667)(1-0.9)=0.0333 \approx 0.033$ for markers $\mathrm{TAGCAC}_{\mathrm{R} 128}$ and $\mathrm{GGACTA}_{\mathrm{S} 254}$, and $(1-0.673)(1-0.9)=0.0327 \approx 0.033$ for markers $\mathrm{ACTCAA}_{\mathrm{R} 136}$ and $\mathrm{GGACTA}_{\mathrm{S} 254}$, i.e., the probability of identifying a resistant plant if either of the markers is used is $0.891,0.967$, and 0.967 , respectively. Therefore, the probability of selecting desirable plants would be enhanced significantly when the markers were used in combination. If the 3 SCAR markers were used simultaneously, the probability of selecting a resistant plant would be enhanced to 0.99 . Our results suggested that the 3 SCAR markers were useful in the MAS programs and could be used in alfalfa breeding programs.

There are still no studies on the inheritance of resistance to CLS caused by P. medicaginis in the autotetraploid alfalfa. A preliminary research was conducted in this study, and the results showed that resistance to the strain used was conferred by a single dominant gene. Different strains of $P$. medicaginis, different plant materials, or different criterion of evaluation of CLS resistance may yield conflicting results in the future, as was shown in the study of inheritance of resistance to downy mildew in alfalfa (Pedersen and Barnes, 1965; Skinner and Stuteville, 1985). Therefore, further research is necessary in this regard.

\section{ACKNOWLEDGMENTS}

Research supported by the National Natural Science Foundation of China (\#30972140) and the National Science and Technology Supporting Project of China (\#2011BAD17B01).

\section{REFERENCES}

Barloy D, Lemoine J, Abelard P and Tanguy AM (2007). Marker-assisted pyramiding of two cereal cyst nematode resistance genes from Aegilops variabilis in wheat. Mol. Breed. 20: 31-40.

Bassam BJ, Caetano-Anolles G and Gresshoff PM (1991). Fast and sensitive silver staining of DNA in polyacrylamide gels. Anal. Biochem. 196: 80-83.

Benchimol LL, de Souza CL and de Souza AP (2005). Microsatellite assisted backcross selection in maize. Genet. Mol. Biol. 28: 789-797.

Brouwer DJ, Duke SH and Osborn TC (2000). Mapping genetic factors associated with winter hardiness, fail growth, and freezing injury in autotetraploid alfalfa. Crop Sci. 40: 1387-1396.

Busbice TH (1968). Effects of inbreeding on fertility in Medicago sativa L. 8: 231-234.

Doyle JF and Doyle JL (1990). A rapid DNA isolation procedure for small quantities of fresh leaf tissue. Focus 12: 13-15.

Fang M, Qinghua Y, Derong S and Jianming G (2008). Selection and validation of ISSR markers of common leaf spot disease resistance-related gene in tetraploid alfalfa. Plant Protection 34: 46-50.

Goodwin SB, Hu X and Shaner G (1998). An AFLP Marker Linked to a Gene for Resistance to Septoria tritici Blotch in Wheat. Proc. 9th Int. Wheat Genet. Symp. University Extension Press, University of Saskatchewan, Saskatoon, 108-110.

Hanson CH, Loper GM, Kohler GD and Bickoff EM (1965). Variation in Coumestrol Content of Alfalfa as Related to Location, Variety, Cutting, Year, Stage of Growth and Disease. U.S. Dep. Agric. Tech. Bull. No. 1333.

Hartl L, Mohler V, Zeller FJ and Hsam SLK (1999). Identification of AFLP markers closely linked to the powdery mildew resistance genes Pmlc and Pm4a in common wheat (Triticum aestivum L.). Genome 42: 322-329.

Irwin JAG, Aitken KS, Mackie JM and Musial JM (2006). Genetic improvement of lucerne for anthracnose (Colletotrichum trifolii) resistance. Australas. Plant Path. 35: 573-579.

Konieczny A and Ausubel FM (1993). A procedure for mapping Arabidopsis mutations using co-dominant ecotypespecific PCR-based markers. Plant J. 4: 403-410.

Mackie JM, Musial JM, Armour DJ, Phan HT, et al. (2007). Identification of QTL for reaction to three races of 
Colletotrichum trifolii and further analysis of inheritance of resistance in autotetraploid lucerne. Theor. Appl. Genet. 114: $1417-1426$.

Michelmore RW, Paran I and Kesseli RV (1991). Identification of markers linked to disease-resistance genes by bulked segregant analysis: a rapid method to detect markers in specific genomic regions by using segregating populations. Proc. Natl. Acad. Sci. U. S. A. 88: 9828-9832.

Morgan WC and Parbery DG (1977). Effects of Pseudopeziza leaf spot disease on growth and yield in lucerne. Aust. J. Agric. Res. 28: 1029-1040.

Morgan WC and Parbery DG (1980). Depressed fodder quality and increased oestrogenic activity of lucerne infected with Pseudopeziza medicaginis. Aust. J. Agric. Res. 31: 1103-1110.

Musial JM, Aitken KS, Mackie JM and Irwin JAG (2005). A genetic linkage map in autotetraploid lucern adapted to northern Australia, and use of the map to identify DNA markers linked to resistance to Phytophthora medicaginis. Aust. J. Agric. Res. 56: 333-344.

Musial JM, Lowe KF, Mackie JM and Aitken KS (2006). DNA markers linked to yield, yield components, and morphological traits in autotetraploid lucerne (Medicago sativa L.). Aust. J. Agric. Res. 57: 801-810.

Musial JM, Mackie JM, Armour DJ, Phan HT, et al. (2007). Identification of QTL for resistance and susceptibility to Stagonospora meliloti in autotetraploid lucerne. Theor. Appl. Genet. 114: 1427-1435.

Nocente F, Gazza L and Pasquini M (2007). Evaluation of leaf rust resistance genes Lr1, Lr9, Lr24, Lr47 and their introgression into common wheat cultivars by marker-assisted selection. Euphytica 155: 329-336.

Obert DE, Skinner DZ and Stuteville DL (2000). Association of AFLP markers with downy mildew resistance in autotetraploid alfalfa. Mol. Breed. 6: 287-294.

Paran I and Michelmore RW (1993). Development of reliable PCR-based markers linked to downey mildew resistance genes in lettuce. Theor. Appl. Genet. 85: 985-993.

Park S, Yoon MK, Lee SS and Kim KT (2007). Development of uniform double-crossed varieties using nearisogenic lines produced by marker-assisted selection in radish (Raphanus sativus L.). HortScience 42: 856-885.

Pedersen MW and Barnes DK (1965). Inheritance of downy mildew resistance in alfalfa. Crop Sci. 5: 4-5.

Yuan QH and Zhang WS (2000). Screening for resistance to common leaf spot in alfalfa germplasms. Acta Pratacul Turae Sin. 12: 52-58.

Yuan QH and Zhang WS (2003). Screening for genetic resistance of alfalfa to Pseudopeziza medicaginis by inoculation of leaf tissue and field evaluation of the plants. Acta Agrestia Sin. 11: 206-209.

Yuan QH, Zhang WS and Min L (2001). Study on excised leaf tissue inoculation of common leaf spot in alfalfa. Acta Agrestia Sin. 9: 21-24.

Raymond WF (1969). The nutritive value of forage crops. Adv. Agron. 21: 1-108.

Skinner DZ and Stuteville DL (1985). Genetics of host-parasite interactions between alfalfa and Peronospora trifoliorum. Phytopathology 75: 119-121.

Skinner DZ, Loughin T and Obert DE (2000). Segregation and conditional probability association of molecular markers with traits in autotetraploid alfalfa. Mol. Breed. 6: 295-306.

Vos Pieter, Hogers R, Bleeker M, Reijans M, et al. (1995). AFLP: a new technique for DNA fingerprinting. Nucleic Acids Res. 23: 4407-4414.

Zhang J, Li X, Jiang G, Xu Y, et al. (2006). Pyramiding of Xa7 and Xa21 for the improvement of disease resistance to bacterial blight in hybrid rice. Plant Breed. 125: 600-605. 